\title{
Smell as a diagnostic marker
}

\author{
K. LIDDELL \\ M.B., Ch.B., M.R.C.P.
}

Department of Dermatology, Royal South Hants Hospital, Fanshaw Street, Southampton SO9 4PE

\begin{abstract}
Summary
The odour emitted by the patient may be one of the first major clues leading to an early diagnosis. Certain dermatological conditions produce an obnoxious smell and several metabolic diseases are associated with a characteristic odour. Schizophrenia and several rare inborn errors of metabolism associated with enzyme deficiencies are linked with distinctive body odour.
\end{abstract}

THE status of body odour has varied with race and time. It is interesting to note that while some races attribute special significance to body odour, e.g. sexual prowess or attraction, history shows that several ancient cultures went to great lengths to eliminate the smell-the Romans by building bath houses all over the Empire, and in many older archaeological sites perfume jars are found. Oddly enough, in direct contrast, the Japanese have virtually no body odour whatsoever. It is recorded that Queen Elizabeth I had perfume in her gloves and surrounded herself with herbs and spices. Toilet waters and colognes were already in common use in the 18 th and 19th centuries and within the last 40 years, deodorants and anti-perspirants have become common in every home.

It is an essential part of the neurological examination to test the patient's sense of smell, and unilateral anosmia can be an excellent sign drawing attention to a frontal lobe tumour. Epileptic patients can experience, just preceding a convulsion, an aura of a strong or unusual smell. These two examples illustrate how the patient's sense of smell can be used as an aid to diagnosis, but no matching emphasis as a diagnostic tool is given to the odour emitted by the patient. An extreme example of how the odour from the patient can be helpful is with regard to the integrity of the sphincters of bladder and bowel. This incontinence may herald a case of dementia, neurological problems such as disseminated sclerosis or cord lesion, a urethrocoele or prostatic disturbance.

The overall smell from a person is derived from the body's secretion and excretion; sweat and sebum from the skin, secretions from the naso-pharynx and lungs; as well as urine, faeces, colonic flatus and vaginal discharge. However, body odour is mainly produced by the apocrine glands' secretion- $\bar{C}$ particularly those in the axilla. Other modified 3 . apocrine glands tend to be maximally situated in the of perineal region and the areola of the breasts. When the secretion reaches the surface of the skin it is or odourless but develops a characteristic, offensive $\vec{\omega}$ odour if left for some hours, owing to bacterial $\stackrel{\circ}{\circ}$ decomposition liberating fatty acids. Sebaceous 은 secretion has some odour and decomposition of $\vec{r}$ products of keratinization-especially when there is hyperhidrosis-can produce an offensive smell. Patients with hyperhidrosis, whatever the underlying cause, can present with an unpleasant body odour bu $\vec{\theta}$ it is unusual for other conditions to present with the $\sigma$ complaint of an obnoxious body smell.

Patients who do present with body odour may be suffering from paranoia, phobias or organic lesions of the central nervous system. It is not surprising that patients with hidradenitis suppurativa leave a $\mathbb{\perp}$ lingering odour in the consulting room, as they have a chronic indolent infection of the apocrine sweat glands. In this condition anti-perspirants are absolutely contra-indicated.

Keeler (1968) highlighted one of the many problems of the Cuna albino Indians in that they cannot sweat normally and emit a repulsive odour likened by their non-albino contemporaries to the smell of a swamp.

Certain other skin conditions are associated with an unpleasant smell, such as vagabond's disease, 을 infected eczema, pemphigus, herpes labialis and herpes zoster. There is said to be a characteristic smell to syphilis, and gangrenous feet can also produce an obnoxious odour. Darier's disease, with $\sigma$ the disturbance in keratin, can produce an unfortu- $N$ nate smell. Fissuring in the thickened areas develops $\underset{\mathrm{C}}{\mathrm{N}}$ and secondary infection occurs and indeed there is a 0 professional awareness of one young woman in the south of England who in the summer months is chased by dogs 'attracted' by the odour (Ross and $\stackrel{?}{?}$ Barrett, 1974).

Odour is a problem in pediculosis owing to matting of body hair with pus and exudate. Vaginal 
malodour may occur with infection or disease in this site. Deep pressure sores on the buttocks extending in the perineum can also be the source of a most unpleasant odour. Leg ulcers which have become infected often have an unpleasant smell. However, a leg ulcer emitting a foul odour may have a more sinister significance-there is, on recent record, a case in which the only reason the patient sought medical advice was on account of the offensive smell from his leg ulcer, and it was found to have undergone malignant change (Liddell, 1975). This is a reinforcement of reports by Levine and Fong (1957) and Dawson and McIntosh (1971) who described a foul smell from varicose ulcers which had become malignant.

Another case of smell being the presenting complaint of cancer was that of a man whose colleagues refused to work with him owing to his offensive body odour (Liddell and White, 1975). He was found to have a necrotic cavity in the site of his penis which had been destroyed by a squamous-cell carcinoma. He had deliberately tried to conceal his condition (fearing venereal disease), allowing it to progress relentlessly, and ultimately presented himself to his G.P. drawing attention only to the body odour. It is possible that some substance was being absorbed from the necrotic lesion and excreted in the eccrine sweat. There is some parallel in the case of a nursing sister who tried to conceal a fungating carcinoma of the breast but the smell produced brought it to light. Again, an elderly lady with an unpleasant odour was found to have a long standing basal-cell carcinoma on her ear, concealed by her hair. Equally interesting, perhaps, is the report by Golding (1965) of bromhidrosis, in a child, due to a foreign body in the nose.

Numerous states of disease are associated with a characteristic odour. Often the first clue to a diagnosis of diabetic ketosis is the fruity aroma of decomposing apples which is mainly attributable to the smell of the ketones on the patient's breath, but it is claimed that the sweat also has a characteristic odour. Foetor hepaticus is found in liver failure and the sweat in gout has a characteristic odour. Patients with typhoid are said to emit a smell comparable to freshly baked brown bread, whereas patients with diphtheria have a sweetish odour. The stench of smallpox is well known and there is on record the diagnosis of smallpox being made when the distinctive odour appeared. The sweat in scurvy is said to have a putrid odour, and patients with scrofula emit a smell like that of stale beer, but patients with yellow fever have an odour which resembles that of a butcher's shop. Uraemia, osteomyelitis, and Fröhlich's syndrome have all been reported to result in characteristic odours. Several diseases of the respiratory tract are associated with unpleasant smells, e.g. bronchiectasis, lung abscesses and ozaena. Gingi- vitis, tonsillitis and Vincent's angina can cause significant odours.

For many years it was claimed that there was a distinctive odour to be found in mental hospitals and it was often attributed to the antisocial behaviour of some of the inmates. However, according to Parkinson (1969), 50 years ago a special room, freshly whitewashed after use, was used at a mental hospital reception centre in Australia to assess doubtful mental cases. The doctor was able to detect a characteristic odour if the patient was suffering from the suspected mental disease. Schizophrenics in particular have long been incriminated as having a pungent body odour but it was not until 1960 that Smith and Sines illustrated that schizophrenic and non-schizophrenic sweat could be distinguished by the odour alone, using rats trained in a reward box. Trans-3-methyl-2 hexenoic acid was found to be the only differing component in schizophrenic sweat as compared to sweat from control subjects. When this chemical substance is added to normal sweat it acquires the odour identical to sweat from a schizophrenic. These significant findings add great weight to the theory that schizophrenia is an inborn error of metabolism.

There are several rare conditions associated with enzyme deficiencies or transport defects which lead to permanent brain damage, unless discovered at a very early age and treated appropriately. Screening tests have been devised but except for phenylketonuria these tests are not generally available. Fortunately some of these conditions are associated with a distinctive odour due to the accumulation of certain metabolites in the body. In the homozygous patient with phenylketonuria there is inability to synthetize phenyl-alanine hydroxylase in an active form leading to hyperphenylalaninaemia and phenylpyruvic aciduria. Phenylacetic acid in sweat and urine produces a musty odour-sometimes described as resembling stale, sweaty locker-room towels. Others describe it as wolflike, mousey or barny.

Another disorder of amino acid metabolism is maple syrup urine disease resulting from defective oxidative decarboxylation of the branched-chain amino acids valine, leucine and isoleucine. Amino and respective keto acids accumulate in the tissues, blood, cerebro-spinal fluid and urine; and the characteristic odour found in the sweat, urine and even the ear wax, usually is apparent towards the end of the first week of life and resembles maple syrup or caramelized sugar. Neurological damage is manifest shortly afterwards and unless the correct diagnosis is swiftly made and dietary management started within the first few days, then it is fatal. There is also an intermittent branch-chained ketonuria-possibly brought on by protein loading due to diet, or catabolic changes of infection. The acute phase of semi-coma 
and fever is accompanied by the maple syrup odour. Fluid administration and dietary changes can be life-saving.

Abnormal body handling of methionine can lead, in the early weeks of life, to convulsions and diarrhoea and a characteristic odour to the urine, sweat and breath. In some cases this odour is reported as sweet but in others it is likened to boiled cabbage.

Smith and Strang (1958) described a flaccid, mentally defective infant with the smell of dried malt or hops. There was also hyperaminoaciduria and the term oast-house syndrome was coined. The odour of the sweaty feet syndrome, described by Sidbury, Smith and Harlan (1967), comprises lethargy, acidosis, convulsions, terminal sepsis and bone marrow depression. The odour of urine, sweat and breath is due to large quantities of butyric and hexanoic acids in the body. Tanaka, Orr and Isselbacher (1968) also described infants who emitted a smell similar to sweaty feet or cheese, owing to the accumulation of isovaleric acid caused by an enzymatic block in leucine metabolism.

Although body odour may be merely physiological and indicate neglect of personal hygiene, or be the outcome of eating garlic or curry, or drinking beer, it seems there are grounds for believing that in some instances it can be pathological.

Already apparatus for sampling skin vapours has been devised, and analysis by gas chromatography enables detection of organic compounds at concentrations below those detected by the human nose. It also has the advantage of detecting non-odorous compounds which may be related to a specific state of disease (Distelheim and Dravnieks, 1973). According to Keele (1963), almost 2,000 years ago Susruta Samhita, one of the originators of ancient Hindu medicine, stated 'by the sense of smell we can recognize the peculiar perspiration of many diseases, which has an important bearing on their identification'. This statement is as true today as it was then. In the U.K., $£ 24$ million/year are now spent on avoiding body odour and who knows what these deodorants and anti-perspirants may be masking?

\section{References}

Brass, A. (1970) Odour of sanity. Journal of the American Medical Association, 212, 472.

CARPENTER, D.G. \& CARTER, C.H. (1970) Inborn errors of metabolism associated with unusual odours. Journal of the Florida Medical Association, 57, 31.

CONE, T.E. (1968) Diagnosis and treatment: some diseases, syndromes and conditions associated with an unusual odour. Pediatrics, Springfield, 41, 993.

Dawson, E.K. \& McINTOSH, D. (1971) Granulation tissue $\frac{\bar{\sigma}}{\partial}$ sarcoma following long-standing varicose ulceration. Journal of the Royal College of Surgeons of Edinburgh, 16, ע)

Distelheim, H.I. \& Dravnieks, A. (1973) A method for $\overrightarrow{0}$ separating characteristics of odours in detection of disease processes. International Journal of Dermatology, 12, 241. $\vec{\omega}$

Freeman, S.K. (1969) Odour and Communication. Annals of $\mathscr{D}$ the New York Academy of Sciences, 163, 410.

Golding, I.M. (1965) An unusual cause of bromhidrosis. 3 Pediatrics, Springfield, 36, 791.

KEELE, K.D. (1963) The Evolution of Clinical Methods in $N$ Medicine, p. 9. Thomas: Springfield, Illinois.

KeELER, C. (1968) Note on sweating and odour of Cuna or albinos. Dermatologia internationalis, 7, 78.

LeVINE, R.M. \& FoNG, F. (1957) Malignant degeneration in varicose ulcers of lower extremities. Canadian Medical 음 Journal, 76, 961.

LidDELL, K. (1975) Malignant change in chronic varicose $\vec{z}$ ulceration. The Practitioner, 215, 335.

LidDELl, K. \& WhiTE, J.E. (1975) The smell of cancer. British Journal of Dermatology, 92, 215.

Parkinson, C.K. (1969) Distinctive odour in mental illne $8 . \vec{c}$ Medical Journal of Australia, 2, 1078.

Ross, A.A. \& Barretr, D.F. (1974) Personal Communicas tion.

Sidbury, J.B., Smith, E.K. \& Harlan, W. (1967) An inborn error of short-chain fatty acid metabolism: the odor of sweaty feet syndrome. Journal of Pediatrics, 70, 8.

Smith, A.J. \& Strang, L.B. (1958) An inborn error of $\frac{0}{D}$ metabolism with the urinary excretion of $\alpha$-hydroxy- $\varrho$ butyric acid and phenylpyruvic acid. Archives of Disease in $\overrightarrow{\bar{\sigma}}$ Childhood, 33, 109.

SMITH, K. \& Sines, J.O. (1960) Demonstration of a peculiar odor in the sweat of schizophrenic patients. Archives of General Psychiatry, 2, 184.

Smith, K., Thompson, G.F. \& Koster, H.D. (1969) Sweat in 흘 schizophrenic patients: identification of the odorous 3 substance. Science, 166, 398.

TANAKA, K., OrR, J.C. \& IsselbaCher, K.J. (1968) Identification of $\beta$-hydroxyisovaleric acid in urine of patient with isovaleric acidemia. Biochimica et biophysica acta, 152, 638 . 